Louisiana State University

LSU Digital Commons

Faculty Publications

Department of Biological Sciences

3-10-2015

\title{
Analysis of the radiation-damage-free $x$-ray structure of photosystem ii in light of exafs and QM/MM data
}

\author{
Mikhail Askerka \\ Yale University \\ David J. Vinyard \\ Yale University \\ Jimin Wang \\ Yale University \\ Gary W. Brudvig \\ Yale University \\ Victor S. Batista \\ Yale University
}

Follow this and additional works at: https://digitalcommons.Isu.edu/biosci_pubs

\section{Recommended Citation}

Askerka, M., Vinyard, D., Wang, J., Brudvig, G., \& Batista, V. (2015). Analysis of the radiation-damage-free xray structure of photosystem ii in light of exafs and QM/MM data. Biochemistry, 54 (9), 1713-1716. https://doi.org/10.1021/acs.biochem.5b00089

This Article is brought to you for free and open access by the Department of Biological Sciences at LSU Digital Commons. It has been accepted for inclusion in Faculty Publications by an authorized administrator of LSU Digital Commons. For more information, please contact ir@lsu.edu. 


\title{
Analysis of the Radiation-Damage-Free X-ray Structure of Photosystem II in Light of EXAFS and QM/MM Data
}

\author{
Mikhail Askerka, ${ }^{\dagger}$ David J. Vinyard, ${ }^{\dagger}$ Jimin Wang, Gary W. Brudvig, ${ }^{\ddagger}{ }^{\dagger}$ and Victor S. Batista ${ }^{\dagger}{ }^{\dagger}$ \\ ${ }^{\dagger}$ Department of Chemistry, Yale University, New Haven, Connecticut 06520-8107, United States, \\ ${ }^{\ddagger}$ Department of Molecular Biophysics and Biochemistry, Yale University, New Haven, Connecticut 06520-8114, United States
}

Supporting Information

ABSTRACT: A recent femtosecond X-ray diffraction study produced the first high-resolution structural model of the oxygen-evolving complex of photosystem II that is free of radiation-induced manganese reduction (Protein Data Bank entries 4UB6 and 4UB8). We find, however, that the model does not match extended $\mathrm{X}$-ray absorption fine structure and QM/MM data for the $S_{1}$ state. This is attributed to uncertainty about the positions of oxygen atoms that remain partially unresolved, even at $1.95 \AA$ resolution, next to the heavy manganese centers. In addition, the photosystem II crystals may contain significant amounts of the $S_{0}$ state, because of extensive dark adaptation prior to data collection.

$\mathrm{P}$ hotosystem II (PSII) is a protein-pigment complex responsible for the production of oxygen in higher plants, algae, and cyanobacteria during the light reactions of photosynthesis. ${ }^{1,2}$ In PSII, the evolution of oxygen proceeds through the catalytic reaction of water oxidation. ${ }^{3,4}$ This process is initiated by absorption of a photon by the chlorophylls called $\mathrm{P}_{680}$, leading to charge separation across the thylakoid membrane. The charge-separated state containing $\mathrm{P}_{680}{ }^{+}$ oxidizes a nearby tyrosine species $\left(\mathrm{Y}_{\mathrm{Z}}\right)$ to form $\mathrm{Y}_{\mathrm{Z}}{ }^{\bullet}$, which in turn oxidizes the oxygen-evolving complex (OEC). The OEC is a $\mathrm{CaMn}_{4} \mathrm{O}_{5}$ cluster in which the metal atoms are connected through $\mu$-oxo bridges, forming a cuboidal $\mathrm{CaMn}_{3} \mathrm{O}_{4}$ core with a dangling $\mathrm{Mn} .{ }^{5,6}$ As the catalytic cycle proceeds, the OEC accumulates oxidizing equivalents, thus evolving through the storage states $S_{n}(n=0-4) .{ }^{4,7}$ During each turn of the cycle, two water molecules are transformed into $\mathrm{O}_{2}$, while four protons are released to the thylakoid lumen, and plastoquinone is reduced to plastoquinol on the acceptor side. The OEC oxidizes water efficiently at low overpotentials, ${ }^{8}$ which makes it a prototype for artificial homogeneous and heterogeneous water oxidation catalysts.

X-ray diffraction (XRD) has been an important method for gaining structural information about the OEC and its surroundings. ${ }^{5,9-13}$ Over the past decade, the resolution of XRD experiments has improved from 3.8 to $1.9 \AA$, revealing the atomic coordinates of the OEC atoms as well as the ligation scheme of coordinated residues and water molecules. ${ }^{5}$ To date, however, all XRD structures that utilized synchrotron radiation have suffered from radiation damage from the X-ray source, leading to $\mathrm{Mn}$ reduction. ${ }^{14}$ These structures of the OEC, including the $1.9 \AA$ resolution structure by Shen and co- workers, ${ }^{5}$ have $\mathrm{Mn}-\mathrm{Mn}$ distances that are longer than those predicted by extended X-ray absorption fine structure (EXAFS) spectroscopy, ${ }^{15-18}$ and computational methods, including density functional theory and quantum mechanics/molecular dynamics (QM/MM). ${ }^{16,19}$

Radiation damage has been recently avoided by using femtosecond X-ray free electron laser crystallography, a process in which a single diffraction pattern is collected from either a single small crystal (or a section of a larger crystal), using very short and very high-energy X-ray pulses. ${ }^{20,21}$ Yano, Yachandra, and co-workers as well as Fromme and co-workers have used this method to study small $(\leq 10 \mu \mathrm{m})$ dark-adapted PSII crystals (presumably prepared in the $S_{1}$ state) and have reported structural models at $6.5 \AA{ }^{22} 5.7 \AA \AA^{23} 5.0 \AA{ }^{24}$ and 4.9 $\AA$ resolution. ${ }^{25}$ By flashing these small crystals with visible light before collecting diffraction patterns, they have reported putative $\mathrm{S}_{2},{ }^{23,25} \mathrm{~S}_{3}{ }^{24,25}$ and $\mathrm{S}_{0}{ }^{25}$ models. However, the intrinsic low resolution of the diffraction pattern has thus far prevented conclusions about changes in the OEC structure. Calculations of electron density difference Fourier maps, ${ }^{23}$ based on $S_{1}$ and $S_{2}$ QM/MM models, however, have shown that the $S_{1} \rightarrow S_{2}$ transition primarily involves changes in the environment of the dangling Mn (Mn4). ${ }^{26}$

Recently, Shen and co-workers used large dark-adapted PSII crystals $(1.2 \mathrm{~mm} \times 0.5 \mathrm{~mm} \times 0.2 \mathrm{~mm})$ to generate a "radiationdamage-free” PSII model at $1.95 \AA$ resolution. ${ }^{6}$ While X-rayinduced $\mathrm{Mn}$ reduction is not an issue for this improved OEC structure, in the work presented here, we show that the simulated EXAFS spectrum of this OEC structure does not match experimental measurements of the $S_{1}$ state. ${ }^{18} \mathrm{We}$ attribute these differences to uncertainty in the positions of the light oxygen atoms, which are not sufficiently resolved even at $1.95 \AA$ resolution, next to the heavy manganese centers (Figure 1A, B). In addition, contributions from the $S_{0}$ state may have been present in the crystals used for $\mathrm{X}$-ray analysis because of extensive dark adaptation prior to data collection.

The first step in our analysis was to determine whether the proposed OEC model reproduces the experimental EXAFS of the $S_{1}$ state, ${ }^{27}$ as simulated by using the $a b$ initio real space Green's function approach implemented in FEFF (version $8.30),{ }^{28}$ because EXAFS measurements use small X-ray doses per irradiated area, leading to negligible photoreduction of the OEC. $^{27,29}$ For the EXAFS simulations (detailed in the

Received: January 29, 2015

Revised: February 18, 2015

Published: February 24, 2015 

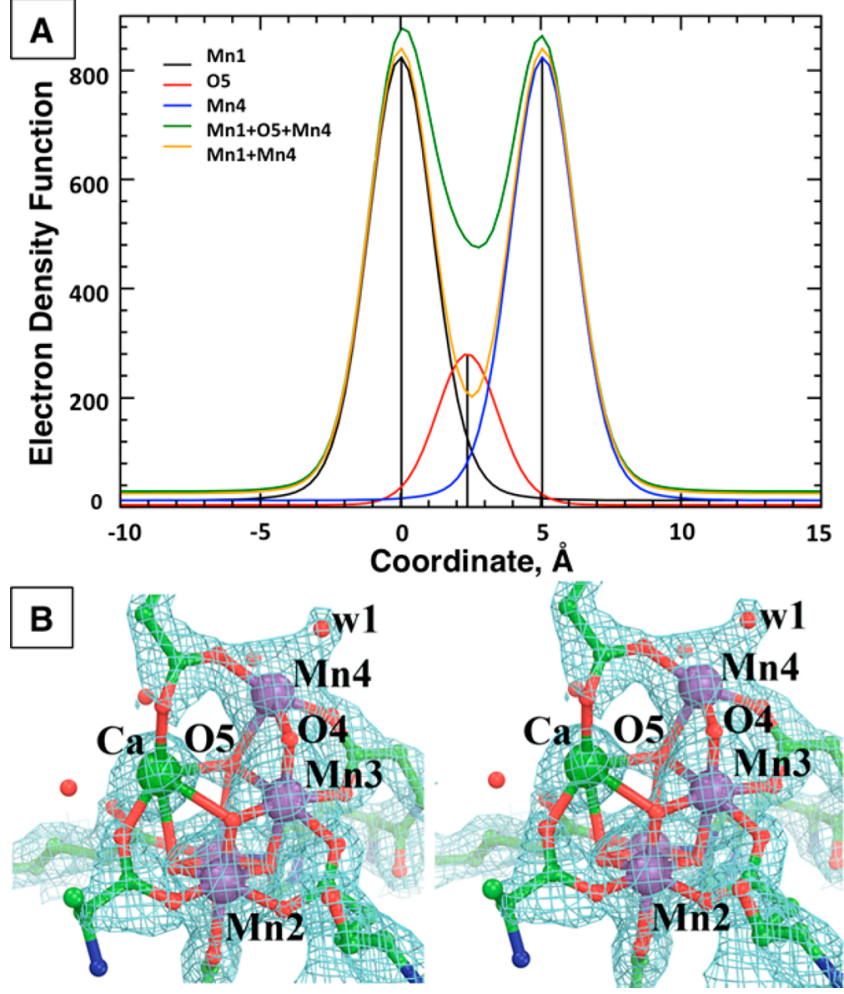

Figure 1. (A) Simulated electron density profile of the Mn1-O5Mn 4 coordinate and (B) stereo diagram of weighted $F_{\text {obs }}-F_{\text {calc }}$ maps using the observed structure factors and corresponding model phases contoured at $2.5 \sigma$ for $4 \mathrm{UB} 8$, monomer B.

Supporting Information), we used the coordinates from the two data sets (4UB6 and 4UB8) for both monomers A and B of PSII. We then compared the simulated EXAFS spectra to experimental EXAFS measurements of the $S_{1}$ state recorded at $20 \mathrm{~K}^{27,29}$ We note that room-temperature and cryogenic EXAFS measurements of the $S_{1}$ state are strikingly similar. ${ }^{18,30}$

Figure $2 \mathrm{~A}$ shows that the spectra obtained with the OEC model of monomers A and B do not match the experimental $S_{1}$ EXAFS spectrum, in agreement with the recent work. ${ }^{18}$ (Figure S1 of the Supporting Information shows the corresponding results in reduced distance space.) In addition, we note that the two monomers are slightly different and predict different EXAFS spectra.

Alignment of the OEC in the two data sets of the two monomers allows for a close inspection of the structural differences among the four reported OEC structures (Figure 2B and Table 1). Table 1 compares the root-mean-square deviations (rmsd's) upon pairwise alignment of all 10 atoms of the $\mathrm{CaMn}_{4} \mathrm{O}_{5}$ OEC core. We note that, on average, the rmsd from alignment of $\mathrm{O}$ atoms is $26 \%$ higher than the average rmsd of all 10 atoms, while the alignment of $\mathrm{Mn}$ is $39 \%$ lower (inclusion of the $\mathrm{Ca}$ atom makes it $36 \%$ lower). Clearly, there is more uncertainty in the positions of $\mathrm{O}$ atoms than in the positions of heavier $\mathrm{Mn}$ and $\mathrm{Ca}$ centers. We hypothesize that the lower precision in the position of $\mathrm{O}$ atoms is due to the limited spatial resolution of those atoms in the OEC structures at the given nominal experimental resolution.

To analyze the intrinsic uncertainty in the position of $\mathrm{O}$ atoms, we consider the OEC structure from monomer $\mathrm{B}$ of 4UB8, which has a Mn4-O5 distance of $2.38 \AA$ and a Mn1O5 distance of $2.70 \AA$. The reported $B$ factors are $24.16 \AA^{2}$ for

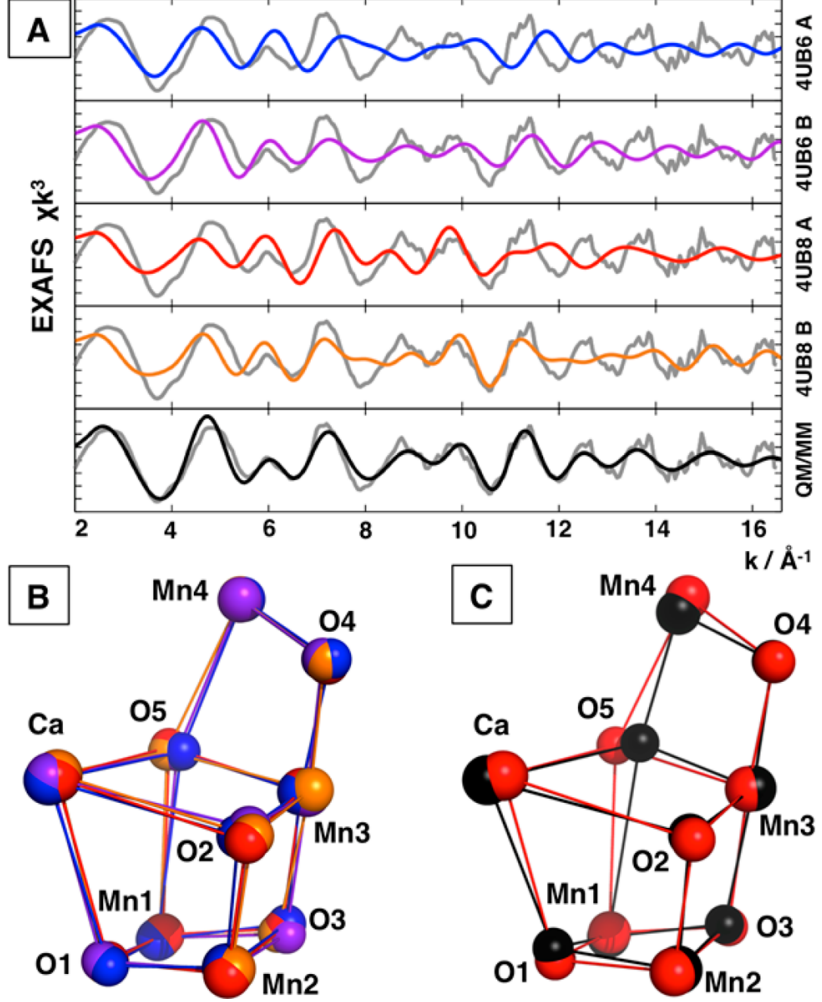

Figure 2. (A) EXAFS spectra simulated from 4UB6 monomer A (blue), 4UB6 monomer B (purple), 4UB8 monomer A (red), and 4UB8 monomer $B$ (orange) ${ }^{6}$ compared to the experimental ${ }^{27} S_{1}$ spectrum (gray). The simulated EXAFS spectrum of our $S_{1} Q M / M M$ model ${ }^{19}$ is shown in black for comparison. (B) Overlay of OEC atoms from 4UB6 monomer A (blue), 4UB6 monomer B (purple), 4UB8 monomer A (red), and 4UB8 monomer B (orange). (C) Overlay of OEC atoms from 4UB8 monomer $A$ (red) and our $S_{1} Q M / M M$ model (black).

Table 1. rmsd's (in angstroms) upon Pairwise Alignment of the OEC Core Atoms in the 4UB6 (monomers A and B) and 4UB8 (monomers A and B) Structures, According to All 10 Atoms in the $\mathrm{CaMn}_{4} \mathrm{O}_{5}$ Core (OEC), Only $\mathrm{Mn}$ and Ca Atoms (Ca and Mn1-Mn4), Only Mn Atoms (Mn1-Mn4), and Only $\mathrm{O}$ Atoms (O1-O5)

\begin{tabular}{|c|c|c|c|c|c|}
\hline & & 4UB6 A & 4UB6 B & 4UB8 A & 4UB8 B \\
\hline & 4UB6 A & 0 & & & \\
\hline$u$ & 4UB6 B & 0.125 & 0 & & \\
\hline ర) & 4UB8 A & 0.092 & 0.120 & 0 & \\
\hline & 4UB8 B & 0.127 & 0.089 & 0.110 & 0 \\
\hline & 4UB6 A & 0 & & & \\
\hline$\Xi \Xi$ & 4UB6 B & 0.055 & 0 & & \\
\hline$=5$ & 4UB8 A & 0.070 & 0.074 & 0 & \\
\hline & 4UB8 B & 0.085 & 0.055 & 0.084 & 0 \\
\hline & 4UB6 A & 0 & & & \\
\hline$\stackrel{1}{=}$ & 4UB6 B & 0.049 & 0 & & \\
\hline$\sum \Sigma$ & 4UB8 A & 0.064 & 0.070 & 0 & \\
\hline & 4UB8 B & 0.079 & 0.049 & 0.091 & 0 \\
\hline & 4UB6 A & 0 & & & \\
\hline on & 4UB6 B & 0.119 & 0 & & \\
\hline$\frac{1}{0}$ & 4UB8 A & 0.183 & 0.162 & 0 & \\
\hline & 4UB8 B & 0.175 & 0.117 & 0.080 & 0 \\
\hline
\end{tabular}

Mn4, $16.73 \AA^{2}$ for O5, and $21.36 \AA^{2}$ for Mn1. Using these distances and $B$ factors at a resolution of $1.95 \AA$, we simulated the error-free electron density profile for the Mn4-O5-Mn1 
coordinate, as shown in Figure 1, for a linear coordinate connecting the three atoms. It is clear that the Mn peaks dominate the signal because $\mathrm{Mn}$ has three times more electrons than $\mathrm{O}$, leading to significant overlap and poor spatial resolution of the positions of the $\mathrm{O}$ atom (Figure $\mathrm{S} 4$ of the Supporting Information shows the simulated electron density profiles for atoms with similar electron counts and smaller $B$ factors). The OEC $\mu$-oxo bridges corresponding to (O4), (O1, $\mathrm{O} 2, \mathrm{O} 3)$, and (O5) are surrounded by two, three, and four metal centers, respectively, with high electron-density signals. Therefore, they are more poorly resolved than the terminal waters bound to $\mathrm{Mn} 4$ and $\mathrm{Ca}$, connected to only one metal and with a longer coordination bond (Figure 1B).

The spatial resolution of light atoms next to heavy atoms is known to be extremely difficult, as documented in other metalloproteins, such as the interstitial carbon atom inside the nitrogenase FeMo cofactor, which required a resolution of 1.16 $\AA$ to resolve it. ${ }^{31,32}$ In fact, this light atom was not discovered in structures at $1.55 \AA$ resolution because it was completely masked by negative Fourier truncation ripple effects. In our study, we find that the light $\mathrm{O}$ atoms next to $\mathrm{Mn}$ atoms, on the opposite, may suffer from positive Fourier truncation ripple effects (see Figure S4F of the Supporting Information) that can deceptively lead to a better resolution of the $\mathrm{O}$ atoms but distort their positions.

In addition to error arising from the $\mathrm{O}$ atom positions, we find that the $\mathrm{Mn}-\mathrm{Mn}$ distances are inconsistent with EXAFS measurements of the $S_{1}$ state. The $S_{1}$ state has three Mn-Mn distances of $2.7-2.8 \AA$ and one that is $\sim 3.2 \AA .^{29,30,33,34}$ As shown in Table 2, the Mn1-Mn2, Mn2-Mn3, and Mn1-Mn3

Table 2. Mn-Mn Distances (in angstroms) in Monomers A and $B$ in the 4UB6 and 4UB8 Data Sets ${ }^{6}$ and Average Deviations from Our Previously Reported $S_{1}$ and $S_{0} Q M /$ MM Models ${ }^{19}$

\begin{tabular}{|c|c|c|c|c|}
\hline & Mn1-Mn2 & Mn2-Mn3 & Mn1-Mn3 & Mn3-Mn4 \\
\hline 4UB6 A & 2.61 & 2.67 & 3.18 & 2.83 \\
\hline 4UB6 B & 2.67 & 2.7 & 3.24 & 2.86 \\
\hline 4UB8 A & 2.68 & 2.77 & 3.12 & 2.83 \\
\hline 4UB8 B & 2.74 & 2.71 & 3.33 & 2.88 \\
\hline $\mathrm{S}_{1 \mathrm{QM} / \mathrm{MM}}$ & 2.73 & 2.76 & 3.26 & 2.68 \\
\hline$\Delta\left(\mathrm{S}_{1 \mathrm{QM} / \mathrm{MM}}-\mathrm{X}\right)$ & 0.055 & 0.047 & 0.043 & -0.17 \\
\hline $\mathbf{S}_{0 \mathrm{QM} / \mathrm{MM}}$ & 2.73 & 2.77 & 3.20 & 2.95 \\
\hline$\Delta\left(\mathrm{S}_{\text {0QM/MM }}-\mathrm{X}\right)$ & 0.055 & 0.057 & -0.017 & 0.100 \\
\hline
\end{tabular}

distances are similar to both experimental EXAFS and our previously reported QM/MM model of $S_{1}$ (Figure 2C), with the largest average deviation being $0.055 \AA$. However, the Mn3-Mn4 vector is significantly $(0.170 \AA)$ longer, which cannot be ascribed to poor resolution. Interestingly, the Mn3$\mathrm{Mn} 4$ distance is one that is expected to become longer when $S_{1}$ is reduced to $S_{0}$ because of the change in oxidation state of $\mathrm{Mn} 3$ from $\mathrm{Mn}^{4+}$ to $\mathrm{Mn}^{3+}$ and the orientation of the resulting Jahn-Teller axis toward O5. ${ }^{19}$

The average Mn3-Mn4 distance of $2.85 \AA$ in the radiationdamage-free OEC structures may be explained if a significant population of reaction centers was poised in $S_{0}$ instead of $S_{1}$. Such sample reduction may occur spontaneously during sample preparation and would not be the result of X-ray-induced reduction. PSII that has been dark adapted for several minutes typically contains $\sim 25 \% \mathrm{~S}_{0}$ and $\sim 75 \% \mathrm{~S}_{1}$ with $\mathrm{Y}_{\mathrm{D}}$ oxidized $\left(\mathrm{Y}_{\mathrm{D}}{ }^{\bullet}\right){ }^{4}$ On the time scale of hours, $\mathrm{S}_{0}$ is oxidized by $\mathrm{Y}_{\mathrm{D}}{ }^{\bullet}$ to produce a population that approaches $100 \% S_{1}$ with $Y_{D}$ reduced. ${ }^{35}$ While kinetically unfavored, $S_{1}$ may be reduced to $S_{0}$ over very long time periods of dark adaptation. For example, the PSII samples used in ref 6 were crystallized over approximately 1 week in the dark.

As detailed in the Supporting Information, we have also simulated the metal-only EXAFS spectra of the four OEC structures and compared them to metal-only EXAFS spectra of $\mathrm{QM} / \mathrm{MM}$ models of $S_{0}$ and $S_{1}{ }^{19}$ in an effort to minimize the influence of $\mathrm{O}$ atoms on the model. However, only marginal improvements in fits were observed for the four OEC structures as compared to linear combinations of $S_{0}$ and $S_{1}$ spectra (see the Supporting Information).

We conclude that the four OEC structures in ref 6 reflect slightly different combinations of $S_{0}$ and $S_{1}$ with a high degree of uncertainty in the position of $\mathrm{O}$ atoms. A substantial population of $S_{0}$ may have accumulated during the very long dark incubations of the samples and is reflected in elongated $\mathrm{Mn3-Mn4}$ distances. The long $\mathrm{Mn}-\mathrm{O} 5$ bond distances observed in the reported structures may be attributed to the protonated form of $\mathrm{O} 5$ as predicted for $\mathrm{S}_{0} \cdot{ }^{19}$ Furthermore, we have shown that the positions of $\mathrm{O}$ atoms close to $\mathrm{Mn}$ centers are difficult to resolve even at $1.95 \AA$, so their assigned positions are likely dependent on the model used to fit the electron density map.

\section{ASSOCIATED CONTENT}

\section{Supporting Information}

Description and analysis of EXAFS simulations and analysis of electron density maps. This material is available free of charge via the Internet at http://pubs.acs.org.

\section{AUTHOR INFORMATION}

\section{Corresponding Authors}

*E-mail: victor.batista@yale.edu. Phone: (203) 432-6672. Fax: (203) 432-6144.

*E-mail: gary.brudvig@yale.edu. Phone: (203) 432-5202. Fax: (203) 432-6144.

\section{Funding}

This material is based upon work supported by the U.S. Department of Energy, Office of Science, Office of Basic Energy Sciences, Division of Chemical Sciences, Geosciences, and Biosciences, via Grants DESC0001423 (V.S.B.) for computational work and DE-FG0205ER15646 (G.W.B.) for experimental work. Crystallographic work was supported by National Institutes of Health Project Grant P01 GM022778 and funding from the Steitz Center for Structural Biology, Gwangju Institute of Science and Technology, Republic of Korea.

\section{Notes}

The authors declare no competing financial interest.

\section{ACKNOWLEDGMENTS}

We acknowledge Dr. Christian F. A. Negre for making an invaluable contribution to the EXAFS simulation methodology.

\section{REFERENCES}

(1) McEvoy, J. P., and Brudvig, G. W. (2006) Chem. Rev. 106, 44554483.

(2) Cox, N., and Messinger, J. (2013) Biochim. Biophys. Acta 1827, 1020-1030. 
(3) Joliot, P., and Kok, B. (1975) Oxygen evolution in photosynthesis. In Bioenergetics of Photosynthesis (Govindjee, Ed.) pp 387-412, Academic Press, New York.

(4) Kok, B., Forbush, B., and McGloin, M. (1970) Photochem. Photobiol. 11, 457-475.

(5) Umena, Y., Kawakami, K., Shen, J.-R., and Kamiya, N. (2011) Nature 473, 55-60.

(6) Suga, M., Akita, F., Hirata, K., Ueno, G., Murakami, H., Nakajima, Y., Shimizu, T., Yamashita, K., Yamamoto, M., Ago, H., and Shen, J.-R. (2015) Nature 517, 99-103.

(7) Forbush, B., Kok, B., and McGloin, M. P. (1971) Photochem. Photobiol. 14, 307-321.

(8) Grabolle, M., and Dau, H. (2005) Biochim. Biophys. Acta 1708, 209-218.

(9) Ferreira, K. N., Iverson, T. M., Maghlaoui, K., Barber, J., and Iwata, S. (2004) Science 303, 1831-1838.

(10) Guskov, A., Kern, J., Gabdulkhakov, A., Broser, M., Zouni, A., and Saenger, W. (2009) Nat. Struct. Mol. Biol. 16, 334-342.

(11) Kamiya, N., and Shen, J. R. (2003) Proc. Natl. Acad. Sci. U.S.A. 100, 98-103.

(12) Loll, B., Kern, J., Saenger, W., Zouni, A., and Biesiadka, J. (2005) Nature 438, 1040-1044.

(13) Zouni, A., Witt, H. T., Kern, J., Fromme, P., Krauß, N., Saenger, W., and Orth, P. (2001) Nature 409, 739-743.

(14) Yano, J., Kern, J., Irrgang, K. D., Latimer, M. J., Bergmann, U., Glatzel, P., Pushkar, Y., Biesiadka, J., Loll, B., Sauer, K., Messinger, J., Zouni, A., and Yachandra, V. K. (2005) Proc. Natl. Acad. Sci. U.S.A. 102, 12047-12052.

(15) Galstyan, A., Robertazzi, A., and Knapp, E. W. (2012) J. Am. Chem. Soc. 134, 7442-7449.

(16) Luber, S., Rivalta, I., Umena, Y., Kawakami, K., Shen, J.-R., Kamiya, N., Brudvig, G. W., and Batista, V. S. (2011) Biochemistry 50, 6308-6311.

(17) Pantazis, D. A., Ames, W., Cox, N., Lubitz, W., and Neese, F. (2012) Angew. Chem., Int. Ed. 51, 9935-9940.

(18) Davis, K. M., and Pushkar, Y. (2015) J. Phys. Chem. B 119, 3492-3498.

(19) Pal, R., Negre, C. F. A., Vogt, L., Pokhrel, R., Ertem, M. Z., Brudvig, G. W., and Batista, V. S. (2013) Biochemistry 52, 7703-7706.

(20) Neutze, R., Wouts, R., van der Spoel, D., Weckert, E., and Hajdu, J. (2000) Nature 406, 752-757.

(21) Chapman, H. N., Fromme, P., Barty, A., White, T. A., Kirian, R. A., Aquila, A., Hunter, M. S., Schulz, J., DePonte, D. P., Weierstall, U., et al. (2011) Nature 470, 73-77.

(22) Kern, J., Alonso-Mori, R., Hellmich, J., Tran, R., Hattne, J., Laksmono, H., et al. (2012) Proc. Natl. Acad. Sci. U.S.A. 109, 97219726.

(23) Kern, J., Alonso-Mori, R., Tran, R., Hattne, J., Gildea, R. J., Echols, N., et al. (2013) Science 340, 491-495.

(24) Kupitz, C., Basu, S., Grotjohann, I., Fromme, R., Zatsepin, N. A., Rendek, K. N., Hunter, M. S., et al. (2014) Nature 513, 261-265.

(25) Kern, J., Tran, R., Alonso-Mori, R., Koroidov, S., Echols, N., Hattne, J., Ibrahim, M., Gul, S., Laksmono, H., Sierra, R. G., Gildea, R. J., Han, G., Hellmich, J., Lassalle-Kaiser, B., Chatterjee, R., Brewster, A. S., Stan, C. A., Glöckner, C., Lampe, A., DiFiore, D., Milathianaki, D., Fry, A. R., Seibert, M. M., Koglin, J. E., Gallo, E., Uhlig, J., Sokaras, D., Weng, T.-C., Zwart, P. H., Skinner, D. E., Bogan, M. J., Messerschmidt, M., Glatzel, P., Williams, G. J., Boutet, S., Adams, P. D., Zouni, A., Messinger, J., Sauter, N. K., Bergmann, U., Yano, J., and Yachandra, V. K. (2014) Nat. Commun. 5, 4371.

(26) Askerka, M., Wang, J., Brudvig, G. W., and Batista, V. S. (2014) Biochemistry 53, 6860-6862.

(27) Grundmeier, A., and Dau, H. (2012) Biochim. Biophys. Acta $1817,88-105$.

(28) Ankudinov, A. L., Bouldin, C. E., Rehr, J. J., Sims, J., and Hung, H. (2002) Phys. Rev. B 65, 104107.

(29) Dau, H., Grundmeier, A., Loja, P., and Haumann, M. (2008) Philos. Trans. R. Soc., B 363, 1237-1243.
(30) Haumann, M., Muller, C., Liebisch, P., Iuzzolino, L., Dittmer, J., Grabolle, M., Neisius, T., Meyer-Klaucke, W., and Dau, H. (2005) Biochemistry 44, 1894-1908.

(31) Einsle, O., Tezcan, F. A., Andrade, S. L. A., Schmid, B., Yoshida, M., Howard, J. B., and Rees, D. C. (2002) Science 297, 1696-1700.

(32) Spatzal, T., Aksoyoglu, M., Zhang, L. M., Andrade, S. L. A., Schleicher, E., Weber, S., Rees, D. C., and Einsle, O. (2011) Science 334, 940.

(33) Yano, J., Kern, J., Sauer, K., Latimer, M. J., Pushkar, Y., Biesiadka, J., Loll, B., Saenger, W., Messinger, J., Zouni, A., and Yachandra, V. K. (2006) Science 314, 821-825.

(34) Dau, H., and Haumann, M. (2008) Coord. Chem. Rev. 252, 273295.

(35) Styring, S., and Rutherford, A. W. (1987) Biochemistry 26, $2401-2405$ 